\title{
Stem Cell Quiescence versus Senescence: The Key for Healthy Aging
}

\author{
Anna Meiliana ${ }^{1,2,3, *}$, Nurrani Mustika Dewi ${ }^{2,3}$, Andi Wijaya ${ }^{2,3}$ \\ ${ }^{1}$ Department of Pharmacology and Clinical Pharmacy, Faculty of Pharmacy, Universitas Padjadjaran, J1. Raya Bandung-Sumedang Km 21, \\ Jatinangor 45363, Indonesia \\ ${ }^{2}$ Prodia Clinical Laboratory, Jl. Supratman No 43, Bandung 40114, Indonesia \\ ${ }^{3}$ Prodia Education and Research Institute, Jl. Kramat Raya No. 150, Jakarta, 10430, Indonesia \\ ${ }^{*}$ Corresponding author. E-mail: anna.meiliana@prodia.co.id
}

Received date: Jul 16, 2021; Revised date: Dec 3, 2021; Accepted date: Dec 6, 2021

\section{Abstract}

$\mathrm{B}$ ACKGROUND: Aging tissues lose their homeostatic and regenerative capacities, which has been linked to the degeneration of the stem cells such as the tissue-specific stem cells, the stem cell niches, and systemic cues that regulate stem cell activity.

CONTENT: The maintenance of tissue homeostatic and regeneration dependent on its tissue-specific stem cells, that - long-lived cells with the ability to self-renew and differentiate into mature cells. Understanding the molecular mechanisms that governs stem cell survival, self-renewal, quiescence, proliferation, and commitment to specific differentiated cell lineages is critical for identifying the drivers and effectors of age-associated stem cell failure.
Such understanding will be critical for the development of therapeutic approaches that can decrease, and possibly reverse and repair the age-related degenerative process in aging tissues.

SUMMARY: The exact mechanisms and reasons of aging process were not fully elucidated until now. Stem cells is one of the keys for maintaining tissues heath and understanding how stem cell decline with age will give us opportunities to find strategy in increasing somatic stem cells regenerative capacity and delay the aging process.

KEYWORDS: adult stem cell, aging, epigenetic, metabolism, quiescence, senescence

Indones Biomed J. 2021; 13(4): 337-49

\section{Introduction}

Homeostatic processes determine an organism's capacity to maintain healthy function during adulthood. Adult tissue stem cells play a critical function in tissue maintenance and regeneration in this multicellular organisms' homeostasis. Thus, stem cell activities reduction has a part of responsibility for the tissue homeostasis imbalance during the post-reproductive lifetime, and is linked to an increase in illness incidence and is caused.(1)

The renewal and differentiation capacity of our tissue stem cells were determined by their specific niches which maintains the stem cells' ability to develop into the cell types of the organ in which they live, and they play a role in the regeneration and homeostasis of almost all tissues throughout life. The stem cell function declined as we age, and different forms of cell-intrinsic damage, as well as changes in the niche and circulating blood, have been shown to contribute to this age-related decline. As multicellular animals' longest-living proliferative cells, adult stem cells are at a higher risk of accumulating DNA mutations and epigenetic changes, which can compromise gene expression fidelity.(1) DNA repair mechanisms in stem cells are not typically more active than in other cells, but the G0 and G1 stages of the cell cycle where more stem cell resides, can be much more error prone. $(2,3)$ These repair mechanisms include metabolic activity suppression to decrease toxic metabolite synthesis within the cell and maintaining a state of quiescence to prevent replication- 
associated DNA damage.(4) Most tissue-specific stem cells, with some notable exceptions, exit quiescence to enter the cell cycle only in response to an increased demand such as in the setting of tissue injury.

Recent data supports a unique theory that stem cell epigenome alterations are caused by accumulated cellintrinsic damage and cell-extrinsic changes in ageing stem cell niches. These accumulated epigenetic changes in stem cells might be the source of developmental pathway dysregulation noticed as people age. As a result, mutant and epigenetically drifted stem cells with altered self-renewal and activities may gain a selective advantage, contributing to the development of age-related organ malfunction and diseases.(1)

\section{Stem Cells and Healthy Aging}

Tissue-specific differentiation patterns are common in stem cells, and their capacity to maintain a balance of quiescence and proliferative activity appears to be important for their survival and maintenance of adequate physiological and regenerative responses.(5) Quiescence has been regarded as a dormant, low-activity state, however current data suggests it is a state of stem cell "idle" and active restraint, anticipate for activation, proliferation, and differentiation. However, stem cells live for a long time in the body, and they are particularly vulnerable to cellular damage, which can eventually lead to cell death, senescence, or loss of regenerative ability. Indeed, stem cells in a variety of tissues have been discovered to experience significant changes as they age, including decreased response to tissue damage, dysregulation of proliferative activities, and decreased functional capabilities. In older species, both in animals and plants, these alterations result in less efficient cell replacement and tissue regeneration.(6)

Recent studies on dynamic interplay between stem cell-intrinsic, environmental and systemic signals showed a possibility for reversibility of aging processes by resetting the genetic or epigenetic 'memory' of aged stem cells and their differentiated cells.(6) This, means to conserve the accumulated DNA damage, proteostasis, toxic metabolites, extracellular signaling and epigenetic remodeling, mitochondrial dysfunction, proliferative exhaustion, which affect the organismal lifespan (Figure 1).

Although stem cells have features (such as a high turnover rate and a specific niche) that may shield them against aging insults, studies also show that stem cells degrade as they get older.(7) Accumulating toxic metabolites and non-autonomous stressors produced by extracellular signals can induce DNA and protein damage which contribute to stem cell function decrease and stem cell pool depletion. Furthermore, any defects in stem cells may be passed down to differentiated cells, resulting in tissue aging. In some

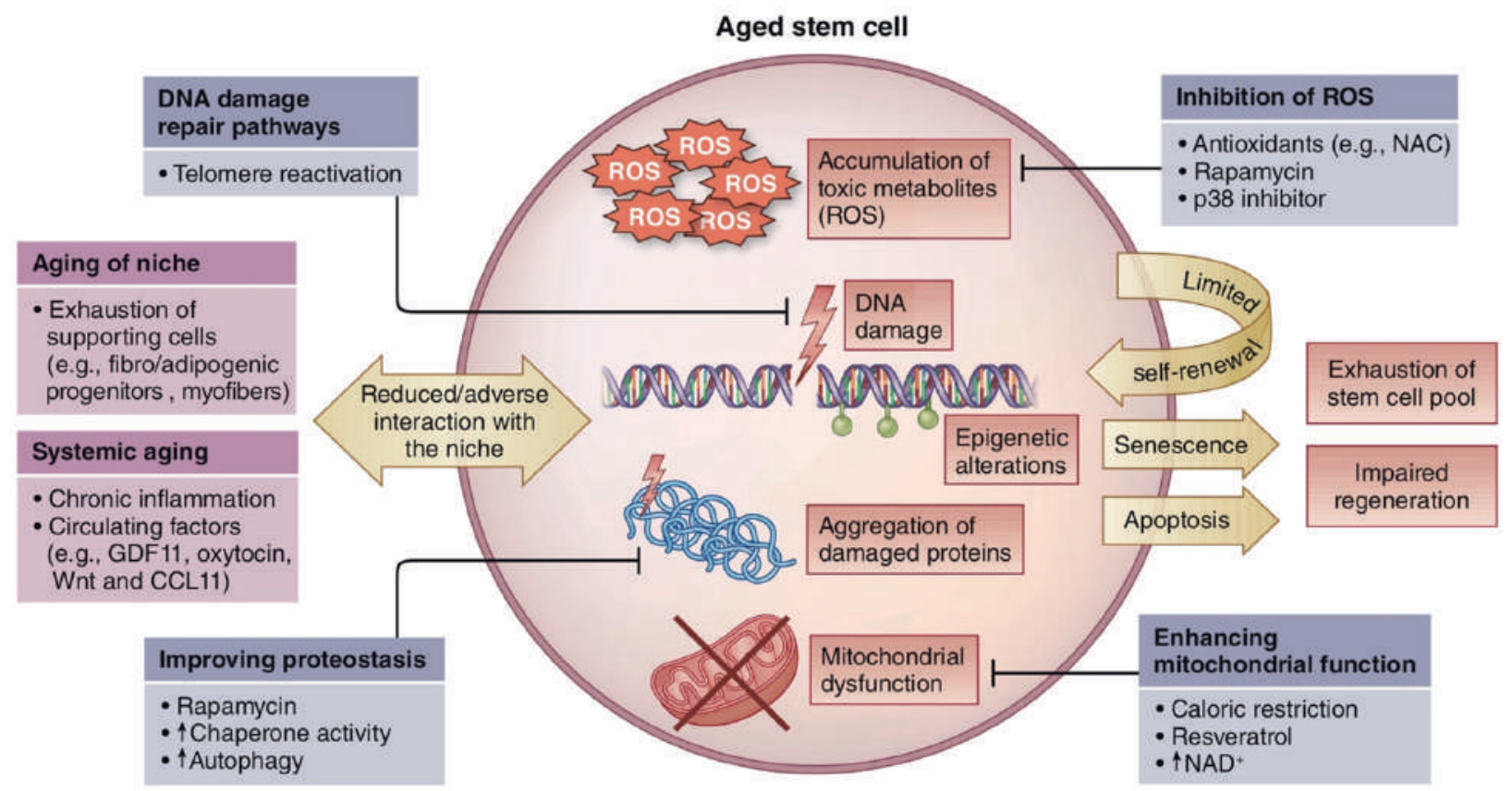

Figure 1. Common pathways contributing to stem cell loss and dysfunction in the aging process.(6) (Adapted with permission from Nature Springer). GDF11: growth differentiation factor 11; CCL11: C-C motif chemokine ligand 11; ROS: reactive oxygen species; NAC: $\mathrm{N}$-acetylcysteine; $\mathrm{NAD}^{+}$: Nicotinamide adenine dinucleotide. 
circumstances, aging phenotypes including sarcopenia, heart failure, and neurodegeneration can be reversed, and the facts that stem cell aging can be reversed have sparked interest in the development of 'rejuvenating' therapies that might help people live longer and healthier lives.

As human lifespans increased, improving the quality of life of seniors becomes increasingly important, even minor improvements might substantially reduce the burden of the health care system and economy for the aging population.(6)

\section{Stem Cell Niche Maintenance During Homeostasis and Regeneration}

Stem cells, which reside in specific microenvironments known as niches, maintain tissue homeostasis and wound healing. Each niche is specifically designed to accommodate the tissue's regeneration demands. Multiple stem cell niches exist in some tissues, such as the epithelium of the skin, or hair follicle, each with its own duty for cellular equilibrium within its domain.(8)

Hematopoiesis is a continuous process of blood cell generation that occurs in the bone marrow through the coordinated proliferation, self-renewal, and differentiation of hematopoietic stem cells (HSCs), followed by the outflow of mature offspring into the circulating blood.(9-12) All blood cells lineage develop from HSC differentiation. (13) The quiescence, proliferation, and differentiation of HSCs are all regulated by a tightly controlled local microenvironment, found inside the bone marrow.(14) Within the niche, regulatory signals come from neighboring cells in the form of bound or released chemicals, as well as vital signs including body temperature, pulse rate, respiration rate, and blood pressure.(12,15,16) HSCs are dormant during homeostasis (17), but any stress such as interferon-mediated signaling will activated it (18-20). Figure 2 shows various cell types responsible in promoting HSC maintenance.

A study tried to restore a hematopoietic milieu inside an ossicle model, where stromal cells are seeded onto a transplanted biomaterial scaffold showed that the bone marrow 'stroma' may begin and maintain hematopoiesis. $(22,23)$ Much progress has been made in determining the niche's cellular makeup. Perivascular cells expressing the melanoma-associated cell adhesion molecule (MCAM, also known as CD146) have been identified as stromal progenitors in the human bone marrow (Figure 2).(24) Platelet-derived growth factor receptor- $\alpha$ (PDGFR- $\alpha$ ), CD51 (also known as Integrin alpha $\mathrm{V}$ (ITGAV)), and the intermediate filament protein nestin are expressed by a minority of CD146 cells in humans and a substantial percentage of perivascular stromal cells in mice. $(25,26)$

Endothelial cells line blood arteries, connect blood and tissues in the bone marrow, and help HSCs maintain and regenerate following injury.(27,28) Endothelial cells are veiled with pericytes or adventitial reticular cells.(29) Endothelial cells and hematopoietic cells may share a similar multipotential progenitor cell, the hemangioblast, according to studies in embryoid bodies $(30,31)$, but there is no evidence that endothelial cells may develop into pericytes (32).

Macrophages also noted as one important nicheregulating cells because of their ability to enhance HSC retention by stimulating the $\mathrm{C}-\mathrm{X}-\mathrm{C}$ motif chemokine 12 (CXCL12) production in nestin-expressing niche cells via an unidentified cytokine. $(33,34)$ In comparison to sympathetic nerves, macrophages have been demonstrated to play a parallel and opposing role.(33) Granulocyte colony-stimulating factor (G-CSF) is one treatment to stimulates the bone marrow microenvironment and mobilize HSCs from bone marrow to the circulation, depletes both macrophages and osteoblastic cells $(34,35)$ and activates sympathetic neurons to release norepinephrine (36).

While controlling stem cell maturation and differentiation, the stem cell niche must maintain its characteristics. $(37,38)$ HSC maintenance is mediated by a complex milieu of factors, and the interactions with other cellular niche elements.(21) Several signaling pathways linked to homeostasis was associated to regeneration, which is regulated in part by the bone marrow vasculature.

One study on aging model (Figure 3) showed that the extrinsic control mediated by the niche causes a shared myeloid progenitor bias, rather than effects induced by agespecific intrinsic HSC alterations.(39) In aged mice, HSCs have been found to localize nearer to the bone surface and farther away from the endosteum, compared to young mice, indicating a microenvironmental balance and potentially affecting their ability to remain quiescent.(40) Similarities between the intestinal crypt, hair, and skin, and other stem cell niche-containing tissues (41-43), may allow us to conclude the advantages of hematopoietic maintenance and regeneration, and will open up intriguing new avenues for better regenerative treatments and rejuvenation methods (21). 


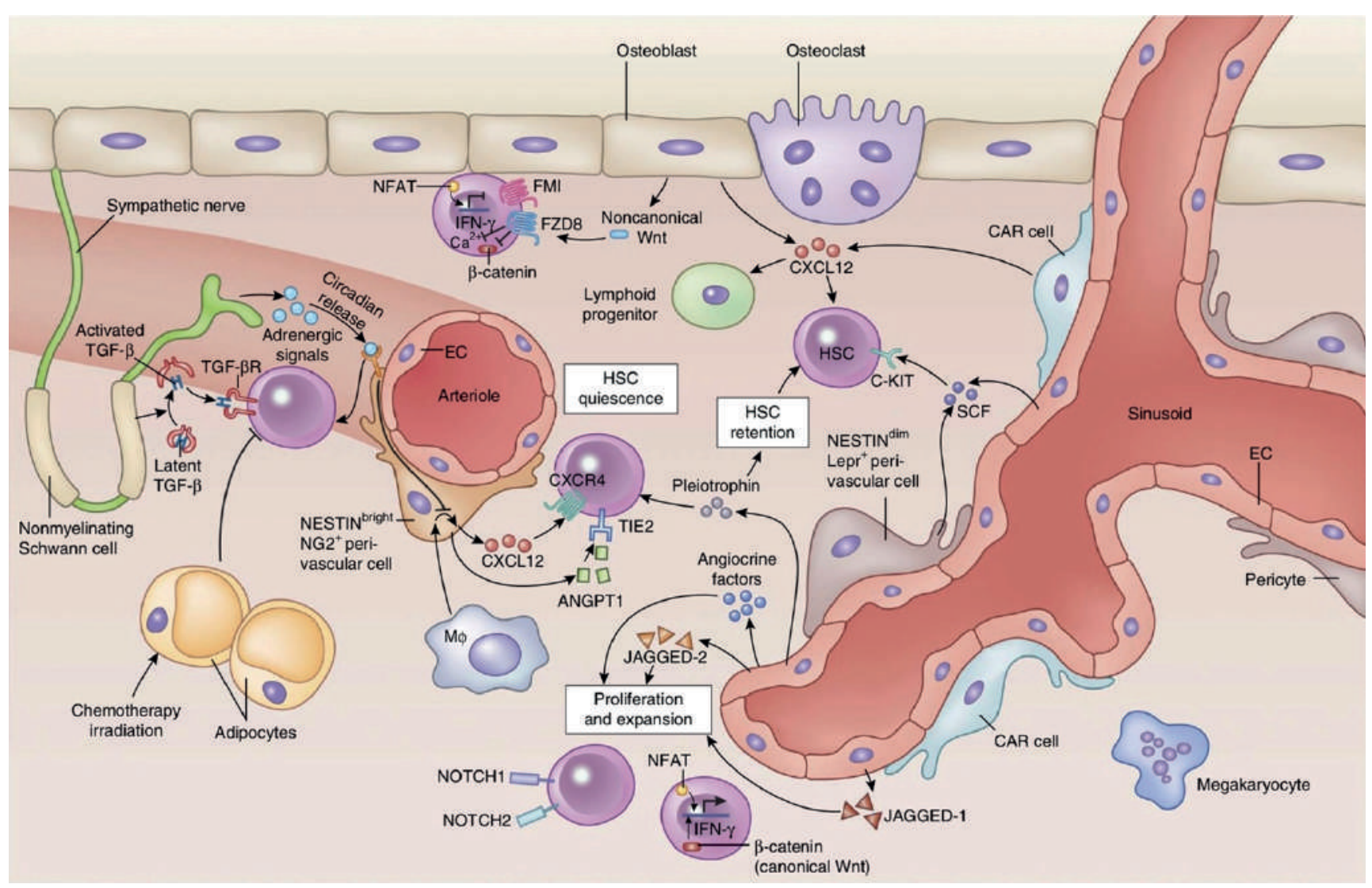

Figure 2. HSC maintenance is mediated by a complex milieu of factors. perivascular stromal cells, endothelial cells, macrophages, CAR cells, sympathetic neurons and nonmyelinating Schwann cells are promoting HSC maintenance while adipocytes gives negative impact on it.(21) (Adapted with permission from Springer Nature). NFAT: nuclear factor of activated T-cells; FMI: Flamingo; FZD8: Frizzled 8; IFN- $\gamma$ : interferon- $\gamma$; Ca2 ${ }^{+}$: calcium; TGF- $\beta$ : transforming growth factor $\beta$; TGF- $\beta$ R: TGF- $\beta$ receptor EC: endothelial cells; NG2+: Neural/glial antigen 2; HSC: hematopoietic stem cell; CXCL12: C-X-C motif chemokine 12; CXCR4: C-X-C chemokine receptor type 4; TIE2: the endothelial-specific receptor, tyrosine kinase with immunoglobulin-like loops and epidermal growth factor homology domains-2; ANGPT1: angiopoietin 1; CAR: chimeric antigen receptors; SCF: stem cell factor.

\section{Geriatric Stem Cells Switch Reversible Quiescence Into Senescence}

Some fractions of adult stem cells can remain in a dormant condition for quite long period of time. While quiescence is not a necessary feature of stem cells, its dysregulation and the loss of its self renewal and differentiation activity frequently can lead to an imbalance in progenitor cell populations, which eventually leads to stem cell depletion. As a result, tissue replacement during homeostasis and after injury is hampered. $(44,45)$

Subpopulations of stem cells are dormant until they are triggered by extrinsic signals, where they started the cell cycle. During G1, a cell's destiny is determined, and cells differentiate, become senescent (stopped proliferating and have been removed from the cell cycle permanently), or return to a quiescent state.(46) Opposite to quiescence, senescence is a degenerative process ensuing a certain cell death.(47)

Senescent cells, unlike apoptotic cells, survive despite "an essentially permanent halt of cell division".(48) In general, senescent cells upregulate cell cycle inhibitors such as p53/p21 and p16INK4a (also known as Cdkn2a) (49), and produce bioactive mediators such as degradative enzymes, inflammatory cytokines, and growth factors, which may contribute to stem cell failure as people age (50). The p16INK4a dysregulation results in stem cells to lose their ability to enter reversible quiescence and become "pre-senescent" such as in geriatric's satellite cells.(51) Thus, silencing p16INK4a restores their quiescence and regeneration capacity, suggesting that this pre-senescent condition may be reversible.(51) Old p16INK4a ${ }^{-/}$HSCs also have greater cell cycle activity and engraftment (52), despite of the risk of a higher rate of malignancy. 


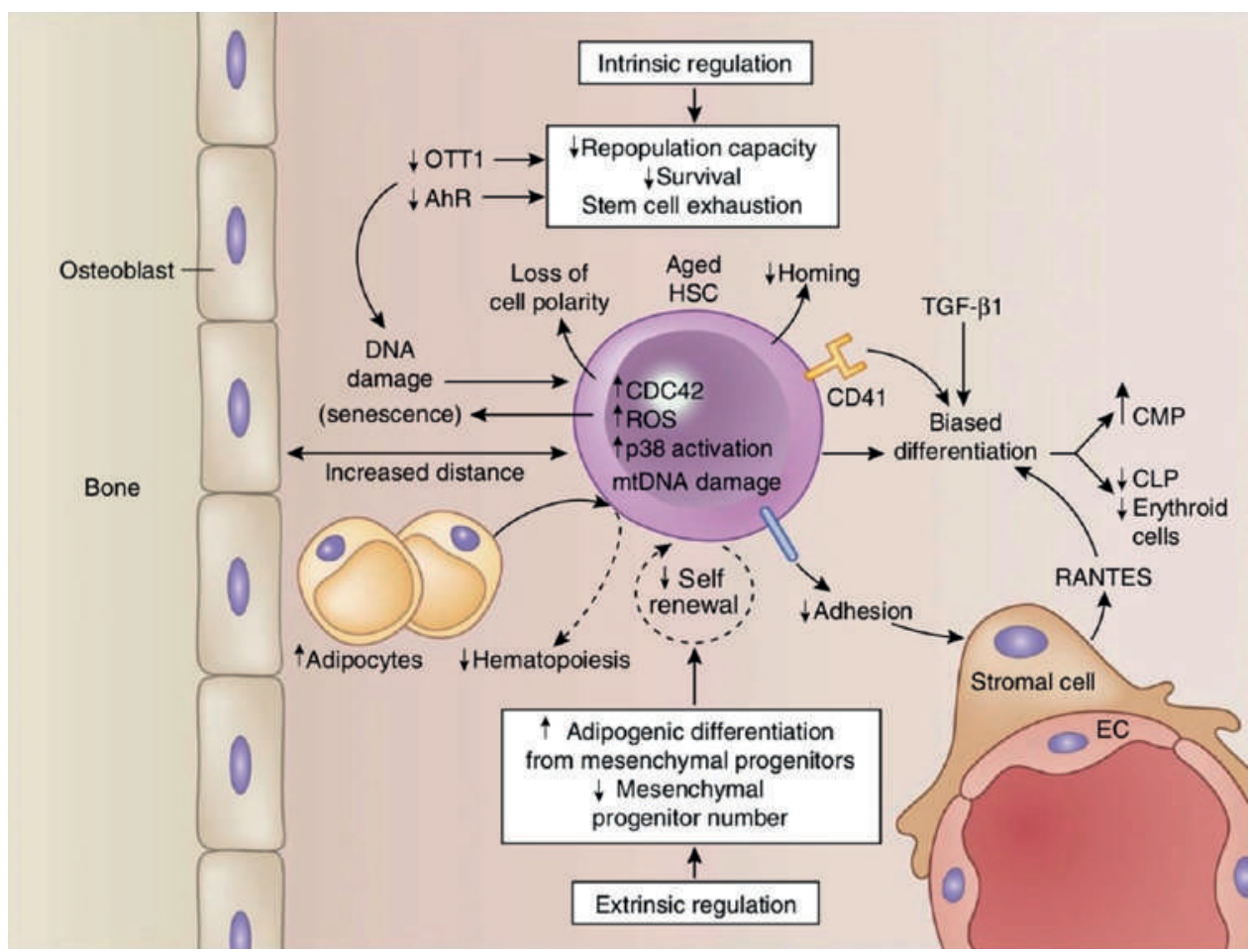

Figure 3. Aging negative effect on HSC both intrinsic and extrinsic mechanisms, lead to reduced hematopoietic activity.(21) (Adapted from Springer Nature). AhR: Ah receptor; HSC: hematopoietic stem cell; CDC42: cell division control protein 42 homolog; ROS: reactive oxygen species; TGF- $\beta 1$ : transforming growth factor $\beta 1$; CMP: common myeloid progenitor; CLP: common lymphoid progenitor; RANTES: regulated upon activation, normal T cell expressed and presumably secreted; EC: endothelial cells.

Senescence may have a role in preventing the development of malignant tumors.(46) Senescent cells secretes many proinflammatory factors such as senescenceassociated secretory phenotype (SASP), and their accumulation in aged tissues causes tissue damage (53), while removing these cells may slow tissue aging (54).

Adult mammalian stem cells have special capability of reversible quiescence, especially in relatively stable tissues with low turnover rate.(55) Sarcopenic muscle in geriatric and progeric mice has an aberrant satellite cell fate due to poor maintenance of the homeostatic quiescence state, which instead flips to a pre-senescence state, inhibiting muscle regeneration potential. In the absence of regeneration need, quiescence appears to be a straightforward means of effectively sustaining the stem-cell population throughout life, particularly in tissues with low turnover, such as skeletal muscle. Sarcopenia, is the most often characteristic found related to aging, especially in geriatrics and people with progeria syndromes.(56) One of the primary causes of physical incapacitation and loss of independence in the older population is the failure of sarcopenic muscle's regeneration mechanism to replace damaged myofibres.(57-59) Satellite cells, a population of muscle-specific Pax7-expressing adult stem cells that are typically dormant, are required for skeletal muscle homeostasis and regeneration.(5) These G0-arrested satellite cells are triggered and enter the cell cycle (R1) when provoked by injury or stress, allowing them to proliferate and produce new fibers or self-renew to replenish the satellite cell (Figure 4).(60,61) In normal circumstances, satellite cell preserves its quiescence by inhibiting irreversible cellcycle withdrawal and so preventing senescence.(51) In old age, the stem cells protective mechanism is failed and enter the cell cycle. $(5,60,62,63)$.

An imbalance of stem cell quiescence and proliferation may potentially contribute to stem cell fatigue. Studies in the Drosophila intestine, as well as HSCs and neural stem cells from p21-null animals (64-66), have shown that maintaining this equilibrium is critical for sustaining the stem cell pool across several rounds of tissue regeneration. Excessive proliferation induced by a lack of cell cycle control causes these stem cell pools to quickly deplete. Increased fibroblast growth factor 2 (FGF2) signaling in the old satellite cell niche causes these cells to lose their quiescence, resulting in decreased muscle regeneration ability.(67) Changes in reactive oxygen species (ROS) levels inside HSCs and perhaps other adult stem cells may also 


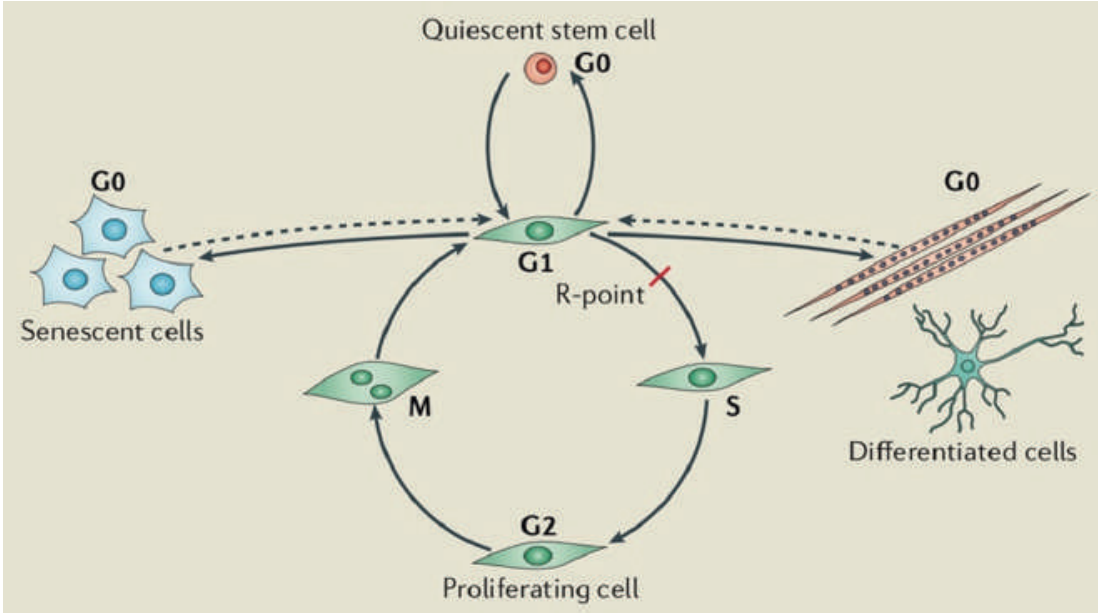

Figure 4. Somatic cells are reversible when they are in G1 (senescent or differentiated) to G0 state (quiescent), and become irreversible once they touched $R$ point then committed to the next round of the cell cycle.(5) (Adapted with permission from Springer Nature). influence the balance between quiescence and proliferation. (68) Quiescence and stem cell maintenance need low levels of ROS, but in the other side ROS also stimulate proliferation and differentiation processes.(69) Therefore, this offers a plausible explanation for how stem cells lose their quiescence and become deficient in older tissues since ROS levels rise with age.

The quiescent stem cells in many tissue compartments are rare, since stem cells are tend to exit their "idle" state and proliferate or differentiate. Low RNA content, absence of cell proliferation markers, and label-retaining cells (LRC) capacity as an indicator of low turnover have all been used to identify quiescent stem cells.(70-72)

The stem cell niche (the stem cells microenvironment which has significant regulatory roles) together with the intrinsic processes is necessary for stem cell maintenance and their quiescence.(73) Recent breakthroughs in genetic methods and high-throughput studies of diverse stem cell subpopulations have yielded significant insights into the molecular markers of quiescent stem cells in many tissue compartments. These results opened up possibilities for discovering and defining regulatory pathways, networks, and drivers of the quiescent state.(5) Although transcriptional and epigenetic profiling may be useful for identifying molecular signatures of quiescent stem cells and identifying pathways involved in the induction or maintenance of the quiescent state, each pathway must be tested in vivo in stem cell quiescence studies to determine its functional relevance.(5) Some transcriptional regulators such as RB, cyclin-dependent kinase inhibitors (CKIs) and p53, and post-transcriptional mechanisms can block quiescent cells to differentiate as described in Figure 5. While Differential mRNA processing alters the susceptibility of mRNAs to miRNA regulation and increasing the protein expression. By knowing these factors it is possible to manage the quiescent state of adult cells.

Environmental stress (for example, oxidative stress induced by the buildup of ROS) can cause harm to longlived, non-dividing quiescent stem cells (74), and damage the cellular components, including DNA. This is a process that has been hypothesized to underpin cell and tissue ageing and lifetime limitation.(75,76) As a result, it appears that quiescent stem cells have developed specialized mechanisms to adapt to external stressors in order to preserve cellular integrity and ensure long-term survival. Quiescent cells rely on autophagic processes for survival, which is consistent with their capacity to perceive and respond to environmental signals related to metabolic status, and autophagy induction appears to be crucial in the control of stem cell activation. Autophagy is a lysosomal degradation mechanism involved in cytoplasmic organelle recycling, which helps cells maintain their health by eliminating damaged components.(77) This means that autophagy is required for HSC quiescence maintenance.(78) Autophagy is also increased in HSCs with Lkb1 knockout, indicating that autophagy may function as a compensatory mechanism to alleviate metabolic stress in these mutants. Understanding stem cell quiescence and the inherent processes by which these cells detect and respond to external cues will definitely assist the development of novel treatment methods focused on improving stem cell activity.(5)

Another problem in geriatric quiescence is autophagy, an evolutionary conserved process in which autophagosomes self-degrade cellular components (organelles, cytosol portions, and misfolded proteins) and deliver them to the lysosomal machinery, preventing waste accumulation. $(79,80)$ In mice, basal autophagy is required to maintain the stem-cell quiescent state.(79-82) Senescence is triggered by 


\section{a Transcriptional regulators}

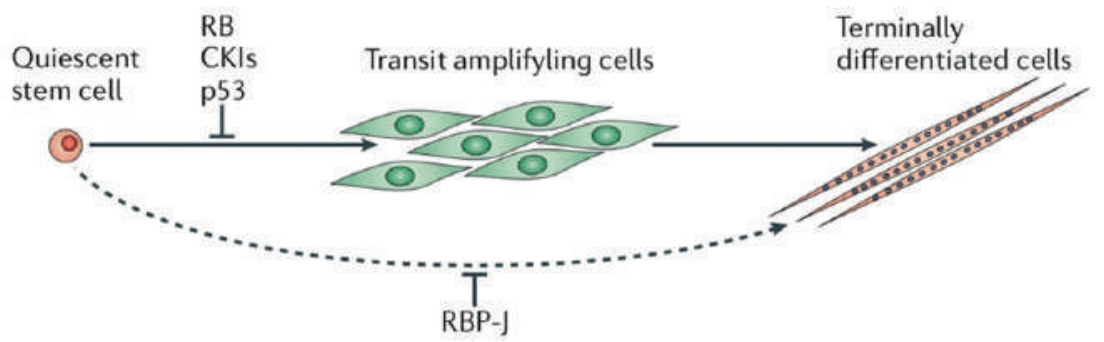

\section{b miRNA regulators}

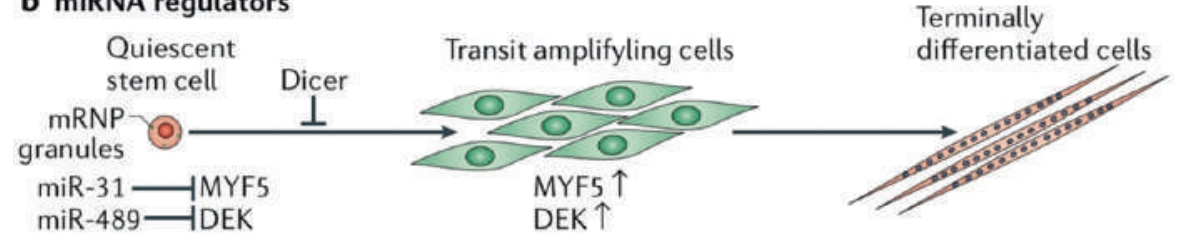

C mRNA processing and translational control

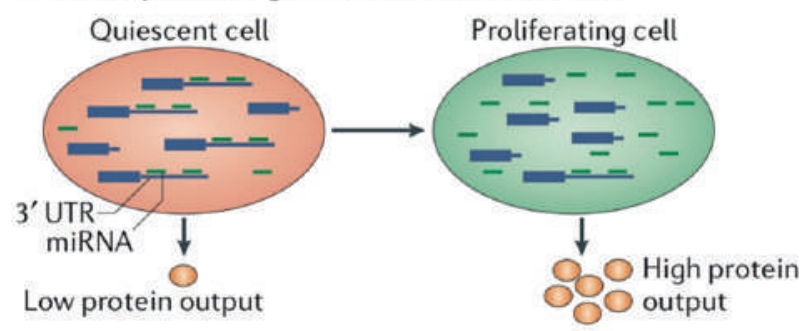

Figure 5. Molecular regulation to keep stem cells quiescence.(5) (Adapted with permission from Springer Nature). RB: retinoblastoma protein; CKI: cyclindependent kinase inhibitors; RBP-J: recombination signal binding protein for immunoglobulin kappa $\mathrm{J}$ region; mRNP: messenger ribonucleoprotein; MYF5: myogenic factor 5 . a loss of proteostasis, increased mitochondrial dysfunction, and oxidative stress in physiologically aged satellite cells or genetically impaired autophagy in young cells, resulting in a reduction in the function and quantity of satellite cells. In geriatric satellite cells, restoring autophagy reverses senescence and restores regenerative capabilities.(83)

\section{Metabolism and Epigenetics Roles in Stem Cell Aging}

Metabolic signal pathways have been found to be substantially linked to aging. Evidence shows that reduced nutritional signaling can increase lifetime, while anabolic signaling speeds up aging; and pharmaceutical treatment of metabolic pathways can enhance organismal lifespan. $(84,85)$ Furthermore, new data shows that cellular metabolic pathways can modify epigenetic states, which can impact organismal aging and lifespan. $(86,87)$

It has recently been proposed that mitochondrial stress-mediated lifespan regulation is linked to epigenetic processes that alter genome function, resulting in an increase in longevity.(88-91) Another study, on the other hand, has discovered that unfolded protein response (UPRmt) is insufficient for Caenorhabditis elegans lifespan extension, and that it may also be involved in the maintenance and propagation of mutant mitochondrial genomes.(92,93) Furthermore, in mice, decreases in nicotinamide adenine dinucleotide $\left(\mathrm{NAD}^{+}\right)$concentration are associated to mitochondrial dysfunction and muscle fiber integrity throughout natural aging. Supplementing with the $\mathrm{NAD}^{+}$ precursor nicotinamide riboside can also help to reverse increasing muscle dysfunction.(94) Finally, it has recently been discovered that exercise protects against age-related secondary damage by preventing mitochondrial respiration decreases.(95) These findings imply that both mitochondrial activity maintenance and mitochondrial function rejuvenation might be effective strategies for delaying aging and increasing longevity.

Another evidence suggesting epigenetics plays a key role in organismal aging.(96-100) The basic structural units of chromatin are nucleosomes, which are made up of DNA wrapped around a group of histone proteins. Gene expression was dynamically regulated by the interaction of transcription factors and epigenetic modifiers. Furthermore, aging of human adult stem cells has been linked to a variety of epigenetic changes, including worldwide loss of $\mathrm{H} 3 \mathrm{~K} 9 \mathrm{me} 3$, de-condensation of centromeric heterochromatin, physical 
telomere attrition, and changes in the nucleolus organizer region related to ribosomal DNA (NOR-rDNA).(101109) Many of the same processes that control aging and proteostasis also control stem cells. $(110,111)$ Because deletion of either Atg7 (78) or Fip200 (112), both of which are required for autophagy, increases ROS levels and depletes HSCs, autophagy is believed to be crucial for HSC maintenance. FoxO, which increases lifespan and stem cell function, regulates aging by transcriptionally activating the expression of various protein-folding chaperones.(113115) There is still a lot of work to be done in order to fully comprehend the processes that control stem cell aging.

\section{Potential Strategies to 'Reverse' Stem Cell Aging}

Because epigenetic processes are reversible, these pathways hold promise as therapeutic targets for agerelated decline and illness.(97) Calorie Restriction (CR) and rapamycin therapy has been shown to impact the lineage determination of stem cells in different organs, including MSCs, in recent research. They reduce the mTOR signaling capacity and other growth factor pathways. $(116,117)$ The $\mathrm{NAD}^{+}$-dependent deacetylase Silent mating type information regulation 2 homolog 1 (SIRT1), and AMP-activated protein kinase (AMPK), may be two key mediators of CR. Both SIRT1 and AMPK appear to play key roles in the cell fate determination of mesenchymal stem cells (MSCs), according to increasing evidence.(116)

Short-term fasting has a similar impact as CR, since it enhances haematopoiesis and reverses the myeloid bias of aged HSCs via inhibiting protein kinase A.(118) Surprisingly, this impact was linked to enhanced HSC function as well as faster HSC proliferation in transplantation trials, two characteristics that are normally adversely connected.(17) SIRT and antioxidant defenses against ROS are directly induced by $\mathrm{CR}$, which also activates fatty acid $\beta$-oxidation (FAO) and enhances oxidative phosphorylation (OXPHOS) efficiency by decreasing oxidative damage.(119-121) As a result, although $\mathrm{CR}$ raises mitochondrial counts and OXHPOS in mice, it also activates SIRT1 and FOXO3, improving muscle stem cells levels and muscle regeneration directly.(122) Antioxidant therapies have demonstrated limited capacity to improve the health or longevity of model organisms, despite the fact that $\mathrm{N}$-acetylcysteine (NAC) can successfully repair some HSC abnormalities linked with unregulated ROS levels.(123) These findings imply that, rather than adjusting ROS levels or metabolic pathways, mitochondrial control and redox state mitigation may be a more effective method for stem cell rejuvenation. It's also been suggested that rapamycin or CR's life-extending benefits are due to the activation of autophagy (123), which reduces ROS levels by eliminating defective or damaged mitochondria. As mitochondrial quality control diminishes with age, such a system would be very useful in the aging body.(124) Finally, the potential that these treatments enhance cellular health by reversing age-related epigenetic alterations over time should be considered.(125,126)

Skeletal muscle stem cells undergo a metabolic switch from fatty acid oxidation to glycolysis during the shift from quiescence to proliferation. Increased H4K16 acetylation and activation of muscle gene transcription result from this reprogramming of cellular metabolism, which lowers intracellular $\mathrm{NAD}^{+}$levels and the activity of the histone deacetylase SIRT1. Increased H4K16 acetylation and unregulated activation of the myogenic pathway in SCs occur from selective genetic deletion of the SIRT1 deacetylase domain in skeletal muscle. Their findings show how metabolic signals may be converted into epigenetic changes that control the biology of skeletal muscle stem cells in a mechanistic way.(127)

Another strategy is cell replacement treatment, which has a lot of potential in terms of restoring tissue homeostasis. However, before cell treatments may be used successfully and safely in clinical settings, aging-related functional degradation and neoplastic change following transplantation must be addressed.(48,128-130) Enhanced techniques need to be formulated to give a stronger regeneration abilities of stem cells with a lower risk of cancer. $(131,132)$ At the specified concentrations, oltipraz, metformin, and resveratrol promoted the proliferation of pre-senescent Werner Syndrome human MSCs (hMSCs) (Figure 6). These three compounds are all known to activate the nuclear factor erythroid-2-like 2 (NRF2) pathways, which is interesting. Furthermore, NRF2 protein abundance was reduced in Werner syndrome or replicative senescent hMSCs. These findings suggest that increasing NRF2 activity might improve hMSC function and longevity.(108)

SIRT6-NRF2-HO-1 axis regulates stem cell redox homeostasis and serves as a transcriptional coactivator. This adds our understanding of SIRT6's role in hMSC redox homeostasis, and might help explain the mechanisms behind a variety of SIRT6-related biological events, such as genomic instability, cellular senescence, cellular transformation, and metabolic dysregulation. SIRT6 is a critical gatekeeper for human adult stem cell homeostasis, implying that the SIRT6-NRF2 pathway might be a promising new target 


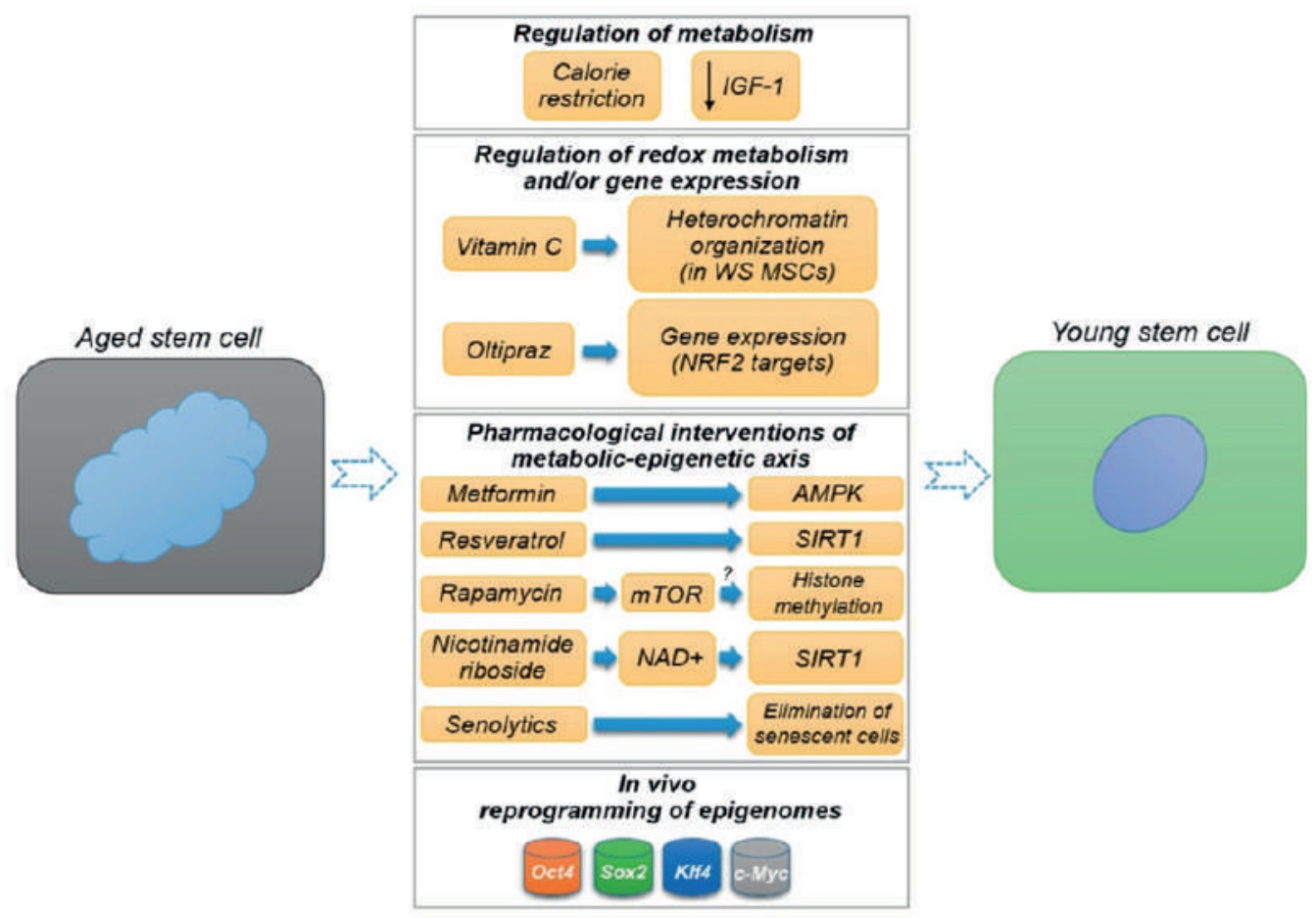

Figure 6. Pharmacological and non-pharmacological potential strategies for the amelioration of stem cell aging.(134) (Adapted with permission from Elsevier Ltd). IGF-1: Insulin-like growth factor 1; MSCs: mesenchymal stem cells; NRF2: nuclear factor erythroid2-like 2; AMPK: AMP-activated protein kinase; SIRT1: sirtuin 1; mTOR: mammalian target of rapamycin; NAD ${ }^{+}$: nicotinamide adenine dinucleotide.

for avoiding aging-related stem cell attrition and, perhaps, treating aging-related diseases.(133)

Metabolic and epigenetic factor can be the possible way to develop any strategies to sway the aged stem cell from senescence to quiescence and preserve the youthful cellular function, combat the age-related phenotypes in dysfunction old tissues, and ameliorating organismal agerelated phenotypes.(134)

\section{Conclusion}

Degenerative diseases are frequently caused by a dysregulation of stem cell activity and a loss in regenerative potential because of aging. The development of methods to preserve stem cell activity and control is thus a viable path for treating a variety of age-related illnesses. The significance of genetic, epigenetic, and metabolic pathways in the control of stem cell activity has been discovered in many species. Treatments that affect cellular metabolism have long been recognized as effective life-extension strategies. How these can be connected with environmental stress to keep stem cells in a state of homeostasis, as well as how environmental stimuli affects stem cell activity will open opportunities for the development of rejuvenation therapeutic strategies.

\section{Authors Contribution}

AM drafted and wrote the manuscript, NMD edited the manuscript, AW proposed the manuscript topic, supervised, and edited the manuscript.

\section{References}

1. Ermolaeva M, Neri F, Ori A, Rudolph KL. Cellular and epigenetic drivers of stem cell ageing. Nat Rev Mol Cell Biol. 2018; 19: 594 610.

2. Mohrin M, Bourke E, Alexander D, Warr MR, Barry-Holson K, Le Beau MM, et al. Hematopoietic stem cell quiescence promotes error-prone DNA repair and mutagenesis. Cell Stem Cell. 2010; 7 : 174-85.

3. Sotiropoulou PA, Candi A, Mascré G, De Clercq S, Youssef KK, Lapouge $\mathrm{G}$, et al. Bcl-2 and accelerated DNA repair mediates resistance of hair follicle bulge stem cells to DNA-damage-induced cell death. Nat Cell Biol. 2010; 12: 572-82.

4. Behrens A, van Deursen JM, Rudolph KL, Schumacher B. Impact of genomic damage and ageing on stem cell function. Nat Cell Biol. 2014; 16: 201-7. 
5. Cheung TH, Rando TA. Molecular regulation of stem cell quiescence. Nat Rev Mol Cell Biol. 2013; 14: 329-40.

6. Oh J, Lee YD, Wagers AJ. Stem cell aging: mechanisms, regulators and therapeutic opportunities. Nat Med. 2014; 20: 870-80.

7. Liu L, Rando TA. Manifestations and mechanisms of stem cell aging. J Cell Biol. 2011; 193: 257-66.

8. Blanpain C, Fuchs E. Plasticity of epithelial stem cells in tissue regeneration. Science. 2014; 344: 1242281. doi: 10.1126/ science. 1242281.

9. Lucas D, Scheiermann C, Chow A, Kunisaki Y, Bruns I, Barrick C, et al. Chemotherapy-induced bone marrow nerve injury impairs hematopoietic regeneration. Nature Medicine. 2013; 19: 695-703.

10. Pietras EM, Lakshminarasimhan R, Techner JM, Fong S, Flach J, Binnewies M, et al. Re-entry into quiescence protects hematopoietic stem cells from the killing effect of chronic exposure to type I interferons. J Exp Med. 2014; 211: 245-62.

11. Lymperi S, Ferraro F, Scadden DT. The HSC niche concept has turned 31: Has our knowledge matured? Ann NY Acad Sci. 2010; 1192: $12-8$.

12. Wang LD, Wagers AJ. Dynamic niches in the origination and differentiation of haematopoietic stem cells. Nat Rev Mol Cell Biol. 2011; 12: 643-55.

13. Warr MR, Pietras EM, Passegué E. Mechanisms controlling hematopoietic stem cell functions during normal hematopoiesis and hematological malignancies: Mechanisms controlling HSC functions. WIREs Syst Biol Med. 2011; 3: 681-701.

14. Morrison SJ, Scadden DT. The bone marrow niche for haematopoietic stem cells. Nature. 2014; 505: 327-34.

15. Adamo L, Naveiras O, Wenzel PL, McKinney-Freeman S, Mack PJ, Gracia-Sancho J, et al. Biomechanical forces promote embryonic haematopoiesis. Nature. 2009; 459: 1131-5.

16. Shin JW, Buxboim A, Spinler KR, Swift J, Christian DA, Hunter CA, et al. Contractile forces sustain and polarize hematopoiesis from stem and progenitor cells. Cell Stem Cell. 2014; 14: 81-93.

17. Passegué E, Wagers AJ, Giuriato S, Anderson WC, Weissman IL. Global analysis of proliferation and cell cycle gene expression in the regulation of hematopoietic stem and progenitor cell fates. Journal of Experimental Medicine. 2005; 202: 1599-611.

18. Essers MAG, Offner S, Blanco-Bose WE, Waibler Z, Kalinke U, Duchosal MA, et al. IFN $\alpha$ activates dormant haematopoietic stem cells in vivo. Nature. 2009; 458: 904-8.

19. Wilson A, Laurenti E, Oser G, van der Wath RC, Blanco-Bose W, Jaworski M, et al. Hematopoietic stem cells reversibly switch from dormancy to self-renewal during homeostasis and repair. Cell. 2008; 135: 1118-29.

20. Baldridge MT, King KY, Boles NC, Weksberg DC, Goodell MA. Quiescent haematopoietic stem cells are activated by IFN- $\gamma$ in response to chronic infection. Nature. 2010; 465: 793-7.

21. Mendelson A, Frenette PS. Hematopoietic stem cell niche maintenance during homeostasis and regeneration. Nat Med. 2014; 20: 833-46.

22. Friedenstein AJ, Chailakhyan RK, Latsinik NV, Panasyuk AF, Keiliss-Borok IV. Stromal cells responsible for transferring the microenvironment of the hemopoietic tissues: cloning in vitro and retransplantation in vivo. Transplantation. 1974; 17: 331-40.

23. Song J, Kiel MJ, Wang Z, Wang J, Taichman RS, Morrison SJ, et al. An in vivo model to study and manipulate the hematopoietic stem cell niche. Blood. 2010; 115: 2592-600.

24. Sacchetti B, Funari A, Michienzi S, Di Cesare S, Piersanti S, Saggio $\mathrm{I}$, et al. Self-renewing osteoprogenitors in bone marrow sinusoids can organize a hematopoietic microenvironment. Cell. 2007; 131: 324-36.

25. Pinho S, Lacombe J, Hanoun M, Mizoguchi T, Bruns I, Kunisaki Y, et al. PDGFR $\alpha$ and CD51 mark human Nestin+ sphere-forming mesenchymal stem cells capable of hematopoietic progenitor cell expansion. J Exp Med. 2013; 210: 1351-67.

26. Méndez-Ferrer S, Michurina TV, Ferraro F, Mazloom AR, MacArthur $\mathrm{BD}$, Lira SA, et al. Mesenchymal and haematopoietic stem cells form a unique bone marrow niche. Nature. 2010; 466: 829-34.

27. Nolan DJ, Ginsberg M, Israely E, Palikuqi B, Poulos MG, James D, et al. Molecular signatures of tissue-specific microvascular endothelial cell heterogeneity in organ maintenance and regeneration. Dev Cell. 2013; 26: 204-19.

28. Kobayashi H, Butler JM, O’Donnell R, Kobayashi M, Ding BS, Bonner B, et al. Angiocrine factors from Akt-activated endothelial cells balance self-renewal and differentiation of haematopoietic stem cells. Nat Cell Biol. 2010; 12: 1046-56.

29. Krause DS, Scadden DT, Preffer FI. The hematopoietic stem cell niche--home for friend and foe? Cytometry B Clin Cytom. 2013; 84: 7-20.

30. Kennedy M, Firpo M, Choi K, Wall C, Robertson S, Kabrun N, et al. A common precursor for primitive erythropoiesis and definitive haematopoiesis. Nature. 1997; 386: 488-93.

31. Shalaby F, Rossant J, Yamaguchi TP, Gertsenstein M, Wu XF, Breitman ML, et al. Failure of blood-island formation and vasculogenesis in Flk-1-deficient mice. Nature. 1995; 376: 62-6.

32. Ono N, Ono W, Mizoguchi T, Nagasawa T, Frenette PS, Kronenberg HM. Vasculature-associated cells expressing nestin in developing bones encompass early cells in the osteoblast and endothelial lineage. Dev Cell. 2014; 29: 330-9.

33. Chow A, Lucas D, Hidalgo A, Méndez-Ferrer S, Hashimoto D, Scheiermann C, et al. Bone marrow CD169+ macrophages promote the retention of hematopoietic stem and progenitor cells in the mesenchymal stem cell niche. J Exp Med. 2011; 208: 261-71.

34. Christopher MJ, Rao M, Liu F, Woloszynek JR, Link DC. Expression of the G-CSF receptor in monocytic cells is sufficient to mediate hematopoietic progenitor mobilization by G-CSF in mice. J Exp Med. 2011; 208: 251-60.

35. Winkler IG, Sims NA, Pettit AR, Barbier V, Nowlan B, Helwani F, et al. Bone marrow macrophages maintain hematopoietic stem cell (HSC) niches and their depletion mobilizes HSCs. Blood. 2010; 116: 4815-28.

36. Lucas D, Bruns I, Battista M, Mendez-Ferrer S, Magnon C, Kunisaki $\mathrm{Y}$, et al. Norepinephrine reuptake inhibition promotes mobilization in mice: potential impact to rescue low stem cell yields. Blood. 2012; 119: 3962-5.

37. Lin H. The stem-cell niche theory: lessons from flies. Nat Rev Genet. 2002; 3: 931-40.

38. Schofield R. The relationship between the spleen colony-forming cell and the haemopoietic stem cell. Blood Cells. 1978; 4: 7-25.

39. Geiger H, de Haan G, Florian MC. The ageing haematopoietic stem cell compartment. Nat Rev Immunol. 2013; 13: 376-89.

40. Köhler A, Schmithorst V, Filippi M-D, Ryan MA, Daria D, Gunzer M, et al. Altered cellular dynamics and endosteal location of aged early hematopoietic progenitor cells revealed by time-lapse intravital imaging in long bones. Blood. 2009; 114: 290-8.

41. Sato T, Clevers H. Growing self-organizing mini-guts from a single intestinal stem cell: mechanism and applications. Science. 2013; 340: 1190-4.

42. Boehnke K, Falkowska-Hansen B, Stark HJ, Boukamp P. Stem cells of the human epidermis and their niche: composition and function in epidermal regeneration and carcinogenesis. Carcinogenesis. 2012; 33: 1247-58.

43. Ito M, Myung P. Dissecting the bulge in hair regeneration. J Clin Invest. 2012; 122: 448-54. 
44. Li L, Clevers H. Coexistence of quiescent and active adult stem cells in mammals. Science. 2010; 327: 542-5.

45. Orford KW, Scadden DT. Deconstructing stem cell self-renewal: genetic insights into cell-cycle regulation. Nat Rev Genet. 2008; 9: 115-28.

46. Campisi J. Cellular senescence: putting the paradoxes in perspective. Curr Opin Genet Dev. 2011; 21: 107-12.

47. Terzi MY, Izmirli M, Gogebakan B. The cell fate: senescence or quiescence. Mol Biol Rep. 2016; 43: 1213-20.

48. Campisi J. Aging, cellular senescence, and cancer. Annu Rev Physiol. 2013; 75: 685-705.

49. Campisi J. Senescent cells, tumor suppression, and organismal aging: good citizens, bad neighbors. Cell. 2005; 120: 513-22.

50. Coppé JP, Desprez PY, Krtolica A, Campisi J. The senescenceassociated secretory phenotype: the dark side of tumor suppression. Annu Rev Pathol. 2010; 5: 99-118.

51. Sousa-Victor P, Gutarra S, García-Prat L, Rodriguez-Ubreva J, Ortet L, Ruiz-Bonilla V, et al. Geriatric muscle stem cells switch reversible quiescence into senescence. Nature. 2014; 506: 316-21.

52. Janzen V, Forkert R, Fleming HE, Saito Y, Waring MT, Dombkowski $\mathrm{DM}$, et al. Stem-cell ageing modified by the cyclin-dependent kinase inhibitor p16INK4a. Nature. 2006; 443: 421-6.

53. Coppé JP, Patil CK, Rodier F, Sun Y, Muñoz DP, Goldstein J, et al. Senescence-associated secretory phenotypes reveal cellnonautonomous functions of oncogenic RAS and the p53 tumor suppressor. PLOS Biol. 2008; 6: 2853-68.

54. Baker DJ, Wijshake T, Tchkonia T, LeBrasseur NK, Childs BG, van de Sluis B, et al. Clearance of p16 Ink4a -positive senescent cells delays ageing-associated disorders. Nature. 2011; 479: 232-6.

55. Dhawan J, Rando TA. Stem cells in postnatal myogenesis: molecular mechanisms of satellite cell quiescence, activation and replenishment. Trends Cell Biol. 2005; 15: 666-73.

56. Burtner CR, Kennedy BK. Progeria syndromes and ageing: what is the connection? Nat Rev Mol Cell Biol. 2010; 11: 567-78.

57. Arthur ST, Cooley ID. The effect of physiological stimuli on sarcopenia; impact of notch and Wnt signaling on impaired aged skeletal muscle repair. Int J Biol Sci. 2012; 8: 731-60.

58. Jang YC, Sinha M, Cerletti M, Dall'Osso C, Wagers AJ. Skeletal muscle stem cells: effects of aging and metabolism on muscle regenerative function. Cold Spring Harb Symp Quant Biol. 2011; 76: 101-11.

59. Renault V, Thornell LE, Eriksson PO, Butler-Browne G, Mouly V, Thorne LE. Regenerative potential of human skeletal muscle during aging. Aging Cell. 2002; 1: 132-9.

60. Yin H, Price F, Rudnicki MA. Satellite cells and the muscle stem cell niche. Physiol Rev. 2013; 93: 23-67.

61. Shefer G, Van de Mark DP, Richardson JB, Yablonka-Reuveni Z. Satellite-cell pool size does matter: defining the myogenic potency of aging skeletal muscle. Dev Biol. 2006; 294: 50-66.

62. Comai G, Tajbakhsh S. Molecular and cellular regulation of skeletal myogenesis. Curr Top Dev Biol. 2014; 110: 1-73.

63. Montarras D, L'honoré A, Buckingham M. Lying low but ready for action: the quiescent muscle satellite cell. FEBS J. 2013; 280: 4036-50.

64. Rera M, Bahadorani S, Cho J, Koehler CL, Ulgherait M, Hur JH, et al. Modulation of longevity and tissue homeostasis by the Drosophila PGC-1 homolog. Cell Metab. 2011; 14: 623-34.

65. Cheng T, Rodrigues N, Shen H, Yang Y, Dombkowski D, Sykes M, et al. Hematopoietic stem cell quiescence maintained by p21cip1/ waf1. Science. 2000; 287: 1804-8.

66. Kippin TE, Martens DJ, van der Kooy D. p21 loss compromises the relative quiescence of forebrain stem cell proliferation leading to exhaustion of their proliferation capacity. Genes Dev. 2005; 19: 756-67.

67. Chakkalakal JV, Jones KM, Basson MA, Brack AS. The aged niche disrupts muscle stem cell quiescence. Nature. 2012; 490: 355-60.

68. Hamanaka RB, Chandel NS. Mitochondrial reactive oxygen species regulate cellular signaling and dictate biological outcomes. Trends Biochem Sci. 2010; 35: 505-13.

69. Owusu-Ansah E, Banerjee U. Reactive oxygen species prime Drosophila haematopoietic progenitors for differentiation. Nature. 2009; 461: 537-41.

70. Hüttmann A, Liu SL, Boyd AW, Li CL. Functional heterogeneity within rhodamine123lo Hoechst333421o/sp primitive hemopoietic stem cells revealed by pyronin Y. Exp Hematol. 2001; 29: 1109-16.

71. Fukada S, Uezumi A, Ikemoto M, Masuda S, Segawa M, Tanimura N, et al. Molecular signature of quiescent satellite cells in adult skeletal muscle. Stem Cells. 2007; 25: 2448-59.

72. Gerdes J, Schwab U, Lemke H, Stein H. Production of a mouse monoclonal antibody reactive with a human nuclear antigen associated with cell proliferation. Int J Cancer. 1983; 31: 13-20.

73. Hsu YC, Fuchs E. A family business: stem cell progeny join the niche to regulate homeostasis. Nat Rev Mol Cell Biol. 2012; 13: 103-14.

74. Rando TA. Stem cells, ageing and the quest for immortality. Nature. 2006; 441: 1080-6.

75. Kregel $\mathrm{KC}$, Zhang HJ. An integrated view of oxidative stress in aging: basic mechanisms, functional effects, and pathological considerations. Am J Physiol Regul Integr Comp Physiol. 2007; 292: R18-36.

76. Rossi AP, Rubele S, Pelizzari L, Fantin F, Morgante S, Marchi O, et $a l$. Effects of brisk walking on physical performance and muscle function in community dwelling elderly women. 2017; J Gerontol Geriatr Res. 2017; 6: 1000399. doi: 10.4172/2167-7182.1000399.

77. Klionsky DJ, Emr SD. Autophagy as a regulated pathway of cellular degradation. Science. 2000; 290: 1717-21.

78. Mortensen M, Soilleux EJ, Djordjevic G, Tripp R, Lutteropp M, Sadighi-Akha E, et al. The autophagy protein Atg7 is essential for hematopoietic stem cell maintenance. J Exp Med. 2011; 208: 45567.

79. Cuervo AM, Bergamini E, Brunk UT, Dröge W, Ffrench M, Terman A. Autophagy and aging: the importance of maintaining "clean" cells. Autophagy. 2005; 1: 131-40.

80. He C, Klionsky DJ. Regulation mechanisms and signaling pathways of autophagy. Annu Rev Genet. 2009; 43: 67-93.

81. Carnio S, LoVerso F, Baraibar MA, Longa E, Khan MM, Maffei M, et al. Autophagy impairment in muscle induces neuromuscular junction degeneration and precocious aging. Cell Reports. 2014; 8: 1509-21.

82. Rubinsztein DC, Mariño G, Kroemer G. Autophagy and aging. Cell. 2011; 146: 682-95.

83. García-Prat L, Martínez-Vicente M, Perdiguero E, Ortet L, RodríguezUbreva J, Rebollo E, et al. Autophagy maintains stemness by preventing senescence. Nature. 2016; 529: 37-42.

84. Fontana L, Partridge L, Longo VD. Extending healthy life span--from yeast to humans. Science. 2010; 328: 321-6.

85. Harrison DE, Strong R, Sharp ZD, Nelson JF, Astle CM, Flurkey $\mathrm{K}$, et al. Rapamycin fed late in life extends lifespan in genetically heterogeneous mice. Nature. 2009; 460: 392-5.

86. Tatar M, Sedivy JM. Mitochondria: masters of epigenetics. Cell. 2016; 165: 1052-4.

87. Berger SL, Sassone-Corsi P. Metabolic signaling to chromatin. Cold Spring Harb Perspect Biol. 2016; 8: a019463. doi: 10.1101/ cshperspect.a019463.

88. Merkwirth C, Jovaisaite V, Durieux J, Matilainen O, Jordan SD, 
Quiros PM, et al. Two conserved histone demethylases regulate mitochondrial stress-induced longevity. Cell. 2016; 165: 1209-23.

89. Tian Y, Garcia G, Bian Q, Steffen KK, Joe L, Wolff S, et al. Mitochondrial stress induces chromatin reorganization to promote longevity and UPRmt. Cell. 2016; 165: 1197-208.

90. Han B, Sivaramakrishnan P, Lin C-CJ, Neve IAA, He J, Tay LWR, et al. Microbial genetic composition tunes host longevity. Cell. 2017; 169: 1249-62.e13.

91. Lin CCJ, Wang MC. Microbial metabolites regulate host lipid metabolism through NR5A-hedgehog signalling. Nat Cell Biol. 2017; 19: 550-7.

92. Lin YF, Schulz AM, Pellegrino MW, Lu Y, Shaham S, Haynes $\mathrm{CM}$. Maintenance and propagation of a deleterious mitochondrial genome by the mitochondrial unfolded protein response. Nature. 2016; 533: 416-9.

93. Matilainen O, Quirós PM, Auwerx J. Mitochondria and epigenetics - crosstalk in homeostasis and stress. Trends Cell Biol. 2017; 27: 453-63.

94. Frederick DW, Loro E, Liu L, Davila A, Chellappa K, Silverman IM, et al. Loss of NAD homeostasis leads to progressive and reversible degeneration of skeletal muscle. Cell Metab. 2016; 24: 269-82.

95. Cartee GD, Hepple RT, Bamman MM, Zierath JR. Exercise promotes healthy aging of skeletal muscle. Cell Metab. 2016; 23: 1034-47.

96. López-Otín C, Blasco MA, Partridge L, Serrano M, Kroemer G. The hallmarks of aging. Cell. 2013; 153: 1194-217.

97. Sen P, Shah PP, Nativio R, Berger SL. Epigenetic mechanisms of longevity and aging. Cell. 2016; 166: 822-39.

98. Benayoun BA, Pollina EA, Brunet A. Epigenetic regulation of ageing: linking environmental inputs to genomic stability. Nat Rev Mol Cell Biol. 2015; 16: 593-610.

99. Booth LN, Brunet A. The aging epigenome. Mol Cell. 2016; 62: 728 44.

100. Pal S, Tyler JK. Epigenetics and aging. Sci Adv. 2016; 2: e1600584. doi: 10.1126/sciadv.1600584.

101. Ren R, Deng L, Xue Y, Suzuki K, Zhang W, Yu Y, et al. Visualization of aging-associated chromatin alterations with an engineered TALE system. Cell Res. 2017; 27: 483-504.

102. Zhang W, Li J, Suzuki K, Qu J, Wang P, Zhou J, et al. A Werner syndrome stem cell model unveils heterochromatin alterations as a driver of human aging. Science. 2015; 348: 1160-3.

103. Liu GH, Barkho BZ, Ruiz S, Diep D, Qu J, Yang SL, et al. Recapitulation of premature ageing with iPSCs from HutchinsonGilford progeria syndrome. Nature. 2011; 472: 221-5.

104. Kubben N, Zhang W, Wang L, Voss TC, Yang J, Qu J, et al. Repression of the antioxidant NRF2 pathway in premature aging. Cell. 2016; 165: 1361-74.

105. Deng L, Ren R, Wu J, Suzuki K, Izpisua Belmote JC, Liu GH. CRISPR/Cas9 and TALE: beyond cut and paste. Protein Cell. 2015; 6: 157-9.

106. Ding Z, Sui L, Ren R, Liu Y, Xu X, Fu L, et al. A widely adaptable approach to generate integration-free iPSCs from non-invasively acquired human somatic cells. Protein Cell. 2015; 6: 386-9.

107. Fu L, Xu X, Ren R, Wu J, Zhang W, Yang J, et al. Modeling xeroderma pigmentosum associated neurological pathologies with patients-derived iPSCs. Protein Cell. 2016; 7: 210-21.

108. Yang J, Li J, Suzuki K, Liu X, Wu J, Zhang W, et al. Genetic enhancement in cultured human adult stem cells conferred by a single nucleotide recoding. Cell Res. 2017; 27: 1178-81.

109. Wang H, Diao D, Shi Z, Zhu X, Gao Y, Gao S, et al. SIRT6 Controls hematopoietic stem cell homeostasis through epigenetic regulation of Wnt signaling. Cell Stem Cell. 2016; 18: 495-507.
110. Buckley SM, Aranda-Orgilles B, Strikoudis A, Apostolou E, Loizou E, Moran-Crusio K, et al. Regulation of pluripotency and cellular reprogramming by the ubiquitin-proteasome system. Cell Stem Cell. 2012; 11: 783-98.

111. Vilchez D, Boyer L, Morantte I, Lutz M, Merkwirth C, Joyce D, et al. Increased proteasome activity in human embryonic stem cells is regulated by PSMD11. Nature. 2012; 489: 304-8.

112. Liu F, Lee JY, Wei H, Tanabe O, Engel JD, Morrison SJ, et al. FIP200 is required for the cell-autonomous maintenance of fetal hematopoietic stem cells. Blood. 2010; 116: 4806-14.

113. Murphy CT, McCarroll SA, Bargmann CI, Fraser A, Kamath RS, Ahringer J, et al. Genes that act downstream of DAF-16 to influence the lifespan of Caenorhabditis elegans. Nature. 2003; 424: 277-83.

114. Oh SW, Mukhopadhyay A, Dixit BL, Raha T, Green MR, Tissenbaum HA. Identification of direct DAF-16 targets controlling longevity, metabolism and diapause by chromatin immunoprecipitation. Nat Genet. 2006; 38: 251-7.

115. Demontis F, Perrimon N. FOXO/4E-BP signaling in drosophila muscles regulates organism-wide proteostasis during aging. Cell. 2010; 143: 813-25.

116. Chen H, Liu X, Chen H, Cao J, Zhang L, Hu X, et al. Role of SIRT1 and AMPK in mesenchymal stem cells differentiation. Ageing Res Rev. 2014; 13: 55-64.

117. Chen J, Astle CM, Harrison DE. Hematopoietic senescence is postponed and hematopoietic stem cell function is enhanced by dietary restriction. Exp Hematol. 2003; 31: 1097-103.

118. Cheng CW, Adams GB, Perin L, Wei M, Zhou X, Lam BS, et al. Prolonged fasting reduces IGF-1/PKA to promote hematopoietic stem cell-based regeneration and reverse immunosuppression. Cell Stem Cell. 2014; 14: 810-23.

119. Salminen A, Kauppinen A, Hiltunen M, Kaarniranta K. Krebs cycle intermediates regulate DNA and histone methylation: epigenetic impact on the aging process. Ageing Res Rev. 2014; 16: 45-65.

120. Martin-Montalvo A, de Cabo R. Mitochondrial metabolic reprogramming induced by calorie restriction. Antioxid Redox Signal. 2013; 19: 310-20.

121. López-Lluch G, Hunt N, Jones B, Zhu M, Jamieson H, Hilmer S, et al. Calorie restriction induces mitochondrial biogenesis and bioenergetic efficiency. Proc Natl Acad Sci USA. 2006; 103: 176873.

122. Cerletti M, Jang YC, Finley LWS, Haigis MC, Wagers AJ. Short-term calorie restriction enhances skeletal muscle stem cell function. Cell Stem Cell. 2012; 10: 515-9.

123. Hekimi S, Lapointe J, Wen Y. Taking a "good" look at free radicals in the aging process. Trends Cell Biol. 2011; 21: 569-76.

124. Mohrin M, Shin J, Liu Y, Brown K, Luo H, Xi Y, et al. A mitochondrial UPR-mediated metabolic checkpoint regulates hematopoietic stem cell aging. Science. 2015; 347: 1374-7.

125. Tanaka Y, Okamoto K, Teye K, Umata T, Yamagiwa N, Suto Y, et al. JmjC enzyme KDM2A is a regulator of rRNA transcription in response to starvation. EMBO J. 2010; 29: 1510-22.

126. Shimazu T, Hirschey MD, Newman J, He W, Shirakawa K, Le Moan $\mathrm{N}$, et al. Suppression of oxidative stress by $\beta$-hydroxybutyrate, an endogenous histone deacetylase inhibitor. Science. 2013; 339: 211-4.

127. Ryall JG, Dell'Orso S, Derfoul A, Juan A, Zare H, Feng X, et al. The NAD+-dependent SIRT1 deacetylase translates a metabolic switch into regulatory epigenetics in skeletal muscle stem cells. Cell Stem Cell. 2015; 16: 171-83.

128. Collado M, Blasco MA, Serrano M. Cellular senescence in cancer and aging. Cell. 2007; 130: 223-33. 
129. Hentze H, Graichen R, Colman A. Cell therapy and the safety of embryonic stem cell-derived grafts. Trends Biotechnol. 2007; 25: 24-32.

130. Wang Y, Han ZB, Song YP, Han ZC. Safety of mesenchymal stem cells for clinical application. Stem Cells Int. 2012; 2012: 652034. doi: 10.1155/2012/652034.

131. Hockemeyer D, Jaenisch R. Induced pluripotent stem cells meet genome editing. Cell Stem Cell. 2016; 18: 573-86.
132. Yamanaka S. Induced pluripotent stem cells: past, present, and future. Cell Stem Cell. 2012; 10: 678-84.

133. Pan H, Guan D, Liu X, Li J, Wang L, Wu J, et al. SIRT6 safeguards human mesenchymal stem cells from oxidative stress by coactivating NRF2. Cell Res. 2016; 26: 190-205.

134. Ren R, Ocampo A, Liu GH, Izpisua Belmonte JC. Regulation of stem cell aging by metabolism and epigenetics. Cell Metab. 2017; 26: $460-74$. 